\title{
Über den Wasserfall
}

In kaum einer chinesischen Landschaft fehlt ein Wasserfall. Besteht das chinesische Doppelzeichen für „Landschaft” (mit dem auch die Landschaftsmalerei bezeichnet wird) aus den beiden Bestandteilen „Berg” (shan) und „Wasser” (shui), so wird im Landschaftsbild die Stelle des Zusammentreffens der beiden Elemente durch den Wasserfall markiert, in dem dies Zusammentreffen seinerseits zeichenhaften Ausdruck annimmt. Oft weisen die gemalten Wasserfälle an ihrem Ursprung eine charakteristische Gabelförmigkeit auf, die an das auf den Kopf gestellte Zeichen 山 (shan) für „Berg” erinnert; es vereinen sich so abbildhafte Darstellung des Wassers und zeichenhafte des Bergs. Die Wasserfälle betonen einen Moment gesteigerter Energie, höherer Lebendigkeit im Ablauf der Bildkomposition, die chinesischen Schriftsteller vergleichen sie gern mit Lebensadern. Sie verbinden die endlose Bewegung des fließenden Wassers mit der unendlichen Ruhe der Bergmassive, einerseits pfeilschnell herabstürzend, besitzen sie doch auch die feierliche Unbewegtheit steinerner Säulen. Es tut not, sie so aufmerksam wie hingegeben zu betrachten, in der Weise, wie dies die chinesischen Maler (etwa in Bildern mit dem - häufigen - Titel Li Bai am Wasserfall des Lushan) wieder und wieder dargestellt haben. Sie bringen dann beim Betrachter die lebendige Geistesenergie gleichsam durch Sympathiezauber zum Fließen. Darüberhinaus muß man ihnen aber auch lauschen. Es gibt Darstellungen, auf denen sich im Schäumen der Gischt chinesische Notenschriftsymbole verbergen. In der Musik des Wasserfalls ist die gesamte menschliche Musik und mehr als diese enthalten, aber sie offenbart sich nur dem Berufenen, der sie aus dem ununterbrochenen Tosen und Tönen herauszulauschen weiß. Doch auch er vermag oft nicht zu sagen, welche Stimme im Klang des Wasserfalls mehr zu ihm spricht: die des Berges oder die des Wassers, die des Raums oder die der Zeit. 